\title{
Malpractice in the Intensive Care Unit
}

\section{Evangelia Michail Michailidou*}

\begin{abstract}
Intensive Medicine Department, Hippokration General Hospital, Senior Student in the Department of Business Administration, University of Macedonia, Masters Degrees, International Medicine-Health Crisis Management, Greece/Member of Health Response team to Crisis Situations of G.H.T. Hippokration
\end{abstract}

*Corresponding author: Evangelia Michail Michailidou, Intensive Medicine Department, Hippokration General Hospital, Se-
nior Student in the Department of Business Administration, University of Macedonia, Masters Degrees, International Medi-
cine-Health Crisis Management, Member of Health Response team to Crisis Situations of G.H.T. Hippokration, Greece

\section{Abstract}

Error in the Intensive Care Unit (ICU) is a welldocumented and frequent problem. This is understandable as one looks at the complexities of serious disease along with the number of invasive and potentially harmful procedures that are commonly used there. Until recently, allegations of medical malpractice resulting from suspected mismanagement in the ICU were unusual, but there has been a rise the last years.

It is difficult to determine whether the increase in lawsuits is due to a real increase in adverse incidents or to a shift in media perception. There is no question that the aggressive cover-up by law companies dealing in personal injury lawsuits offering to initiate claims on a contingency fee basis has become more common. The Medical Protection Society is experiencing an increasing number of claims generally, and the value of damages awarded is skyrocketing [1].

This includes the insufficient number of ICU beds in the public sector and the acute lack of appropriate nurses in both the public and private sectors. More troubling are the obstacles faced by nurses to apply for critical care and the limited number of critical care nurses graduating. Coupled with a high rate of turnover due to burn-out and greater work openings in other industries and overseas, this leads to a situation where even private ICUs fail to staff their units and retain standards. The mixture of high bed occupancy, chronically ill patients and novice nurses provides the ideal atmosphere for errors and incidents that can lead to lawsuits for damages. The condition is not any different on the medical side. The quality of treatment is that critically ill patients should be treated in ICUs by a team of health providers headed by critical care practitioners with specialty in Intensive Care. Not only surgeons, internists or anesthesiologists without specialization in Intensive Care, which they close holes in the gaps of the health system and do not have the proper education. We are all accustomed to thinking in terms of our primary specialty but this carries many risks. Intensive care training offers the skill to treat the patient comprehensively and systematically, something very important in patients of ICU. Although, we have to mention that there were few unexpected variations in malpractice claims occurring in ICU because of specific medical specialty. Preventive efforts should concentrate on procedures, regardless of the medical specialty, including:

1. Retaining procedural skills,

2. Well-framing of procedural hazards, and

3. Adequately describing post-procedural complications. Skills that are either innate or can be developed through ICU specialization training.

While critically ill patients in the private sector are frequently handled by separate and not suitable always, physicians, these doctors prefer to see the patient at different times of the day, give contradictory orders, and make their own private records. There is no team work usually. Also, under the best of conditions, ICU management often - one would say eventually - results in 'iatrogenic' disorders. John Marshall pointed out that critical disease is potentially iatrogenic and it only exists in people who have survived a life-threatening medical procedure. In addition, the entire structure of serious illness is focused on the effects of original resuscitation attempts or the outcomes of procedures that are regularly conducted in the ICU. It is 
difficult to determine the limits between cause and effect and between acceptable complications and preventable negligence [2-5].

Patients who survive a lengthy stay in the ICU are rarely left with life-long complications as a result. Prolonged muscle fatigue, neurological disabilities, and post-traumatic stress disorder involving both the patient and the family are usually described. Who can blame the patient for his anger?

Patients are most frequently admitted to intensive care as a result of an iatrogenic case. Researches showing that more than 21 per cent of admissions had a previous iatrogenic case, the most common being adverse drug disorders, postoperative illnesses and complications of surgical procedures. Personal injury attorneys extend the net extensively and ICU workers may be accused, particularly if the long-term condition is not specifically linked to the initial injury [6].

How do we defend ourselves from legal action that can be both socially and psychologically crippling, not to mention financially catastrophic, if one is not insured? Guidelines and protocols are not always solutions. Hospital managers appreciate directives because they transfer the responsibility to either the writer or the person who failed to obey [7].

The instructions have a position, but are of no value if they are out of date, so impractical that they cannot be complied with or agreed by the workers. There will never be a rule for any case, and there can be no formula for intensive care. By all means have basic rules, but they must be practical, versatile, approved and revised on a regular basis. The most critical thing is to uphold high professional expectations. This means ensuring that all medical professionals and nurses who treat chronically ill patients are critical care experts. In addition, they need to remain up to date with the constantly evolving field of critical care medicine. A multidisciplinary in-house academic curriculum is a positive start [8].

Second, intensive care administration should be focused on a team. The ICU team includes nurses, surgeons, dieticians, physiotherapists and others who contribute to patient care on a regular basis [9]. The team needs a leader, preferably an intensivist, who supports a 'flat hierarchy' and a transparent and efficient contact mechanism. This includes a joint management round where the different practitioners will offer feedback and remind, criticize and help each other [10].

Even a supreme chief cannot defeat a team when it comes to decision-making. Harmonious teaming often ensures that the patient and the family do not get mixed reports about the patient's success and anticipated results. Holding good notes is necessary, not only as the most effective defensive tool in the (no doubt unlikely) case of a legal problem, but also as part of the contact on patient management. Notes should not only document clinical observations and incidents, but also the explanation why decisions have been taken. It is advisable to retain a copy of one's own reports and share them with colleagues in the patient's hospital folder [11-13].

Finally, maintaining a positive relationship with the patient's family is incredibly necessary, not only to get them navigate emotionally tough times, but also because they are the patient's proxy decision makers. Families need details, but the mistake of overwhelming them with medical care should be avoided. It is more important to give them time to pose questions. It is not generally possible to build a connection with the patient when they are seriously ill, so a follow-up visit after they have left the ICU is an important way to link with them at a personal level and at the same time give them an explanation of what has happened and what the potential effects are. In the case of patients who have died in the ICU, the interpersonal relationship that has developed with their relatives throughout their hospitalization [14].

We ought to have in our mind that most of malpractice cases are brought not out of malpractice or even because of concerns about the quality of medical treatment, but as an indication of frustration about any aspect of patient-doctor or doctor-relatives relations and contact. Intensivists who consider and will react adequately to the emotional needs of their patients are less likely to be sued $[15,16]$. This can also be transformed into a more accomplished practice of medicine by those doctors who are most mindful of the importance of a positive relationship.

\section{References}

1. American Medical Association (2020) Critical care medicine. Specialty overview web site.

2. Quinn GR, Ranum D, Song E (2017) Missed diagnosis of cardiovascular disease in outpatient general medicine: insights from malpractice claims data. Jt Comm J Qual Patient Saf 43(10): 508-516.

3. Myers LC, Gartland RM, Skilling, J et al (2020) An examination of medical malpractice claims involving physician trainees. Acad Med 95(8): 1215-1222.

4. Myers LC (2020) Toward preventing medical malpractice claims related to chest procedures. Ann Am Thorac Soc 17(6): 776-779.

5. U.S.Census Bureau (2018) Census regions and division of the 
United States. Published 2010.

6. United States Department of Labor (2018) Consumer Price Index Databases. Published 2018.

7. Wallace DJ, Angus DC, Seymour CW, Barnato AE, Kahn JM (2015) Critical care bed growth in the United States. A comparison of regional and national trends. Am J Respir Crit Care Med 191(4): 410-416.

8. Halpern NA, Goldman DA, Tan KS, Pastores SM (2016) Trends in critical care beds and use among population groups and Medicare and Medicaid beneficiaries in the United States: 2000-2010. Crit Care Med 44(8): 1490-1499.

9. The Leapfrog Group (2020) ICU physician staffing. Updated April 1, 2018.

10. Leapfrog Hospital Safety Grade (2020) Updated February 1, 2020.

11. Arriaga A, Gawande A, Raemer D (2014) Pilot testing of a model for insurer-driven, large-scale multicenter simulation training for operating room teams. Ann Surg 259(3): 403-410.

12. Saugel, B, Scheeren, TWL, Teboul, JL (2017) Ultrasoundguided central venous catheter placement: a structured review and recommendations for clinical practice. Crit Care 21(1): 225.

13. Elmer J, Lee S, Rittenberger JC, Dargin J, Winger D et al. (2015) Reintubation in critically ill patients: procedural complications and implications for care. Crit Care 19(1): 12.

14. Anesthesia Quality Institute (2020) Closed claims bibliography. Published 2017.

15. Kachalia A, Kaufman SR, Boothman R (2010) Liability claims and costs before and after implementation of a medical error disclosure program. Ann Intern Med 153(4): 213-221.

16. Tan EC, Chen DR (2019) Second victim: Malpractice disputes and quality of life among primary care physicians. J Formos Med Assoc 118(2): 619-627.

*Corresponding author: Evangelia Michail Michailidou, Email: evamichailidou@yahoo.gr

Next Submission with BGSR follows:

- $\quad$ Rapid Peer Review

- Reprints for Original Copy

- E-Prints Availability

- Below URL for auxiliary Submission Link: https://biogenericpublishers.com/submit-manuscript/ 